\title{
Reflective Panorama of Social Education as a Mission of the Community Health Agent
}

\author{
Maykon Anderson Pires de Novais \\ Department of Informatics in Health \\ Federal University of São Paulo (Unifesp) \\ Brasil \\ Chennyfer Dobbins Abi Rached \\ Professional Master's Program in Management in Health Systems \\ Nove de Julho University (UNINOVE) \\ Brasil \\ Paola Zucchi \\ Department of Medicine \\ Discipline of Economics and Management in Health \\ Federal University of São Paulo (Unifesp) \\ Brasil \\ Márcia Mello Costa De Liberal \\ Department of Medicine \\ Discipline of Economics and Management in Health \\ Federal University of São Paulo (Unifesp), Brasil \\ Center for Humanities \\ Faculty of Social and Applied Sciences \\ Federal University of West Bahia (Ufob) \\ Brasil
}

\begin{abstract}
This article presents an analysis from the theoretical point of view on the evolution of the concept of Social Education. In order to do so, it evaluates the interdisciplinary characteristics involved in this proposal of engagement with society, elucidating and clarifying the governmental and non-governmental initiatives directed to the health area in Brazil, especially regarding the work developed by Community Health Agents as educators through a program of actions and procedures ensured by the implementation of the Family Health Program. As the work carried out by the groups of assistance to the populations, especially the less favored ones, is a set of activities interconnected and supported in each other, it is possible to follow the chain of each task force, whose purpose is to contribute to the well-being and promoting the quality of life throughout all Brazilian territory.
\end{abstract}

Keywords: Society, Social Education, Health, Community Agent

\section{Introduction}

The central focus of Social Education has been base on the main social segments with respect to the traditional training for the exercise of this activity, which leaves much to be desire as regards the effectiveness necessary for a quality result. It happens because today's society immersed in the irreversible context of the globalized economy and the precepts of postmodern culture presupposes a new paradigm evidenced by the extreme vulnerability of the individuals inserted in the citizenship process. This condition promotes the convergence of thoughts and procedures in urban spaces, with the aim of create a model still unheard of from the point of view of educational agents through social intervention engaged and conscious of its function. Considering this new reality, it is possible to affirm that Social Education has been highlighting itself as a scientific area to base and develop pedagogical intervention projects that promote quality of life in society. 
In this context, the Social Educators are configured as preventive agents, inserted with children, adolescents, young people, elderly and vulnerable groups or at risk, mainly in the promotion of programs of socio-educational support to deprived populations. These professionals enjoy the same status as other educators, since the educational essence transcends the school scope, since it requires the acquisition of a theoretical and practical training for the development of skills in planning, intervention and evaluation in the field of Social Education. As well as in the understanding of the relationship between Education and Social Support, especially regarding the implementation of community intervention projects through activities among population segments that need special care from the governmental and private spheres.

In addition, it is necessary to design organizations in their diverse social, cultural and educational contexts, with the intention of engaging the community in this process by establishing partnerships through formal and informal networks. In this way, the professional work of the Social Educator must cover a broad spectrum of employability in public and private educational institutions. The focus is on social integration and health care, with emphasis on local authorities in the school community and in other segments of society, because of its preventive nature and intervening in critical situations focused on the well-being of the entire population.

So the social educator is been inserted in several types of actions, such as the framework of cases of abandonment, problematic family environment and early intervention during early childhood. Also included in this context the cooperation in projects and other activities developed in the school environment, with a view to the primary prevention of violence and deviant behavior, as well as the healthy occupation of idle time through counseling with adolescents. Also part of this context is the participation in programs of socio-labor inclusion of students with special educational needs, support for the search for traineeships, for jobs and for development of cultural and sports initiatives. They cover assistance to families in the resolution of their problems social, emotional and socio-educational, support to the elderly population for the promotion of their sociability, socioeducational intervention in the hospital context, including the prevention and recovery of toxic addicts and alcoholics, as well as re-education of juvenile delinquency and support actions populations at risk of marginalization (Zappe \& Dias, 2010).

\section{Health Education: Quality of Life Increase in Brazil}

Even though it is evident in the current context from the socioeconomic point of view, there is still no closed consensus to define and delimit the field of action of Social Education, as well as its field of intervention. Based on the presuppositions of Psychology, it is an education directed to the social development of the people. In this case, the fundamental aspect is been directly related to the agents that are part of the diverse social contexts. In this sense, the references come from the pedagogical area due to the adoption of the criteria of formal education, non-formal education, and informal education.

In spite of all these theoretical assumptions, education as a process of emancipation, in interaction with social movements in practice, has a function at once creating and transforming reality as the crucial element found in Paulo Freire's thought, which influenced the Movement of Popular Education in the area of Health throughout Latin America and, especially, in Brazil. Initially, it is necessary to consider Health Education as a field of proposals and disputes of projects of society and worldviews that is updated in the forms of conception and organization of discourses and practices related to education in the field of health (Freire, 2014).

According to Cardoso de Melo's view (2007), in order to assimilate the theoretical conceptions about health education, it becomes necessary to understand the concepts related to education, health and society and to establish the underlying relationships between them. It is also necessary to add the need to observe and analyze these concepts in the interface with the concepts regarding health work and its relations with the agents of work as an educational factor. Based on these theoretical assumptions the categories of education, health and work analysis should be understand and adopt as social practices as part of the production of human existence, approaching the phenomena inherent to it from the historical point of view, such as producers, reproducers or transformers of social relations. In this scenario, health education is conducive to varied conceptions that are still been confronted in the work practice of the various health professionals that are part of the Unified Health System (UHS). It is worth emphasizing that this confrontation occurs mainly in the ways of thinking the human being in its multiple capacities of interaction and the forms of social organization taking into account the division of the goods produced in the current political-economic conjuncture and in the reforms promoted by the State. 
This questioning was crucial in the 1990s, through the valorization of the social educator assumed by several countries, since, even though it was present since the 1970s, the positive vision of this professional became clearer from the second half of the 1980s.

In Brazilian society, the issue of social education in general terms has been receiving the necessary attention, thanks to the weight and intervention of the State in the national economy. In addition, the state apparatus concentrates attributions and is been shaped by the plastering and the excess of regulatory bureaucracy. For this reason, in the 1990s, a set of actions was been developed to overcome crises, including measures such as fiscal adjustment, market-oriented economic reforms and social security reform, as well as the social policy. This reform is part of the role assigned to the State, since it takes on the role of promoting and regulating economic development and no longer control it by the direct exercise of power and decentralization to the non-state public service sector. Even it does not involve the exercise of State power, although they need their support, as in the case of activities related to health, education, culture and scientific research.

Nevertheless, certain crucial issues in implementing these innovative measures in the field of health require further evaluation and change, as some of the characteristics of health service organizations deserve to be analyze in order to identify facilities or difficulties related to the adoption of a managerial model to the detriment of others. In this sense, service organizations geared to the health sector can be describe as professional organizations that control their own work and are able to influence administrative decisions.

According to this new conception, the State reform altered the area of human resources of the Health Unique System (HUS), making the labor relations governed by the contract of stability in employment were transformed into relations more flexible and without stability, which gave rise to different forms of employment relationships and of differentiated remuneration plans according to each specific situation. As such, the strands of this policy, although still under the control of the federal administration, allowed states and municipalities, through their guidelines and proposals, also to act in a regionalized and localized manner.

In 2002, the Ministry of Health invested in contracting the Community Health Agents, as this is the most appropriate professional profile, so that municipal public power could establish a form of partnership with a social organization, with a view to developing the programs in this area. The improvement of this change can be perceive by the numerous possibilities to bring civil society closer to a service model that is consistent with the development of public health in Brazil, and to guarantee the preservation of the social rights of agents, without departing from constitutional principles. An example of this was the work carried out by the Routes Project, which included the Municipal Plan for Childhood and Youth and the Municipal Plan for Confronting Child and Juvenile Sexual Violence (Campinas, 2003).

In order to observe the interface between the fields of action, with the objective of establishing an inter-sectoral and interdisciplinary proposal, the initiative was been outlined based on the following guidelines (Lopes \& Malfitano, 2006, p.32):

- Prevent - offering cultural and sports activities for adolescents, constituting spaces for coexistence in neighborhoods and fostering associative groups and / or cooperatives.

- Search and diagnose - implement a unified information system; conduct an active search of children and adolescents at known points, through social educators.

- Caring for and protecting - offering medical, psychological, therapeutic-occupational, corporal work, complementary therapies, STD / AIDS prevention, harm reduction, etc. Legal support, foster home, family return, financial aid for protection (grant aid).

- Train - train professionals involved in the project and the local network of social facilities (public servants and NGOs, neighborhood leaders and adults).

- Communicate - production of informative and educational material, dissemination in the official media and in the media.

- Supervise - create a network of aid among public institutions that have, among their missions, oversight, such as the Guardianship Council, the Ministry of Labor, the Public Prosecutor's Office, the Childhood and Youth Court, and the Women's Police Station, among others.

- Gestar - follow-up of actions, accountability, fund raising Management is been carried out through coordination for each axis and of a collegiate. 
As the characteristics of the community health agent profile are fundamental to their activities, many Brazilian municipalities have found in this type of service the exit for the hiring of new professionals, providing a faster and more efficient expansion. It also regulated the situation of about 800 thousand workers who were working in precarious conditions in the HUS, in the most diverse contractual modalities. Still in this context of professionalization and development of the provision of services to all population, it is worth remembering that the Brazilian Constitution of 1988 introduced health as a right of every citizen. For this reason, the creation of the HUS was important for the emergence of two fundamental movements in its policy in Brazil, which shifted from one social insurance standard to another social security, with an emphasis on curative medicine for a model of attention and integrality, which can already be find in the sanitary reform.

Soon after the regulation of the legal provisions for health in 1990, however, the lack of an agreement related to the initial structure of SUS led to a scenario of resistance crises in all its stages of implementation. With this, social policies aimed at health have undergone basic changes in terms of national, regional and state integration, which gave rise to a local focus, according to which the selected locus should be consider as the only space capable of responding in a more to meet the needs of disadvantaged populations. As such, the country has revealed a resumption of the community viewpoint, according to which individuals and families take responsibility for their welfare conditions in society. In this context, the community health agent, as well as the nuclear agent, work together to ensure support to communities through the implementation of basic actions whose commitment is to expand and strengthen health efforts.

Currently, the Community Health Agents (CHA) program can be consider as part of the Family Health Strategy Program. The creation of the Community Agents of Health Program (CAHP) occurred in 1991, emphasizing the process of changes in the health sector in order to encourage prevention and health promotion, and to increase access to the system. This endeavor has consolidated itself as an articulating instrument between health services, communities and the most diverse forms of knowledge that make up this relationship at a structural level. Thus, it is up to the CHA to use the tools to perform the demographic diagnosis of each community, including the feasibility of activities focused on health education.

In addition, it has the tasks of collecting and recording data that is been used to control and plan actions, encourage community participation in health policies and make home visits with a certain periodicity, without losing sight of other policies capable of promoting quality of population life. In Brazil, starting in 2004, the program began to qualify thousands of community health agents throughout the country at different times for each state, using the three spheres of HUS management. In the States, this program is under the responsibility of technical schools and human resources training centers.

As in the United States, this type of initiative acts as an instrument of social inclusion, considering the perspective of social mobility in the context of the community linked to the area covered by the Basic Health Unit to which the action was been linked. This objective was been supported by the theoretical reference in the field of sociology, as well as the establishment of a methodology appropriate to these efforts. The theoretical support was been based on studies that focus on the phenomenon of social inclusion related to mobility and social accessibility. The category social representation provides the formulation of the main concept for the construction of social reality, since it allows a more accurate understanding of how subjects construct social reality, orienting themselves through it, which is a product of collective character. This reflection presupposes the existence of a dynamic pedagogical practice, provided by the richness of the exchanges between the most diverse popular knowledge and the daily experiences. In this sense, the qualification program for the community agent has as scope not only the consolidation of the health care policy in force in Brazil, but also to collaborate in the construction of a "propulsive knowledge" that aims at the historical and cultural amplitude of praxis in the Health area. By professionalizing the actions of its agents, the Ministry of Health seeks the legitimacy of this practice based on a specific knowledge and the insertion of the CHA, in order to guarantee more supremacy to local governments.

In this way, the community agents become increasingly visible within the localities for which they provide services, standing out as active subjects of the procedures already assimilated and approved by society, which make it stand out as a local citizen. This strategy of action in professional terms highlights the knowledge acquired within the local community and, together with formal knowledge, promotes the adhesion of users to health services, establishing a two-way connection with the effort of the public sphere. 
Praxis, that is, the application of practice results in a critical elaboration, capable of placing both thought and action in a permanent process of improvement ((Silva \& Whitaker Dalmaso, 2002).

Thus, transforming structural dynamics becomes vitally important thanks to scientific progress and the advancement of technology. Therefore, the daily knowledge associated with formal knowledge, outlines the guidelines that guide the work of the CHA, in addition to serving as a contextual basis for an exclusive formation. It is worth remembering that the insertion of plural knowledge from the community itself into the programmatic content of the CHA formation reveals a favorable scenario so that it can be and feel like authority. In the view of the sociologist Max Weber (1999), it is the knowledge related to mastery and practical application that determines the established authority as a legitimating force and able to lead to the obedience of the established rules. Thus, "It is a 'professional culture' expressing the conceptions and the practices that shape a professional group and the structure of services directed to the collective body." (Machado, 1996, p.36).

This two-way street controls the professional practice by delimiting the competence of the community agent to overcome such obstacles. In addition, consensual agreements must be establish during the training of agents and recognized as the result of knowledge recognized and built by the professionals themselves during the course, providing unity of the team as a whole. For this reason, the changes that the qualification provides to the work performed by the CHA collaborate to highlight the existence of a professional authority built and established by the interaction with the community. Therefore, each member of the team plays a specific role, according to the acquired competence of a knowledge already established in the community in question.

This integration of plural knowledge results in a process-oriented practice involving health, disease, and community care as a transformative practice. In this aspect, current community agents formulate their principles with the bond and co-responsibility that are been debated together with the users who hold the local knowledge, in order to overcome the limits determined by traditional practices, as well as the formation of new social subjects. This training also has the power to make it easier to establish links with users, transforming them into partners and citizens capable of collaborating in the creation of healthy public policies that go far beyond the use of technologies aimed only at curing diseases that are been diagnosed.

Based on these premises, the professionalization of community agents transcends the production of knowledge and its social function with the communities, since it becomes responsible for the establishment of a new social locus, more committed to reducing inequalities. Therefore, in the field of health, each service can and should be consider as an innovative practice that aims to reduce the tension generated by the lack of preparation of most societies to apply the necessary health procedures to the most diverse layers of the needy populations. It can been affirmed, then, that the program of training of community agents fulfills its social function through the introduction of new technologies and the opening of the space to listen and think strategies of action that can revert for the benefit of all.

In this way, professionalization functions as a means for individuals to gain the right to exercise a given productive activity and, at the same time, create unusual possibilities of social mobility within the communities served. For this reason, the policy of professional education of which this program is part can clearly discern that one cannot separate work, health services and the production of knowledge as if they were watertight universes. This ends up generating collective responsibility for consistency in educational actions and health services provided to a specific community.

\section{Education: Strategic Tool in the Family Health Program}

In the last three decades, Primary Health Care (PHC) is been increasingly noticed and developed on the world stage, as a strategy to structure the networks of integrated health care services, in the search for the creation of "effective health systems." Throughout this period, experiences in more developed and developing countries have already proven that the Family Health Strategy (FHS) increases the effectiveness of Health Care by reducing costs, satisfying families and communities. Therefore, it is a health system structured according to the principles and organizational bases of PHC, whose main objective is to improve the quality of life and health of the families linked to it. For this reason, the World Health Organization (WHO) has advocated PHC since the 1978 Alma-Ata Declaration "Health for All" as an effective strategy to ensure equity in health and human development. 
It is very important to recall that in the 1990s, the Ministry of Health launched the PSF in Brazil as a national primary care policy to promote the reorganization of services and reorientation of care practices, health promotion, prevention and rehabilitation of the citizens. Thus ratifying the doctrinal principles of equity, integrality and universality; and the organizational principles: decentralization, regionalization, participation and social control.

In this sense, care in the Basic Health Unit (BHU) or in the home, was carried out by the Family Health Team (FHT), compose by doctors, nurses, nursing auxiliaries and community health agents, creating bonds of shared responsibility. It is also worth mentioning that the research carried out on the Personnel Engagement Modes show a diversity of institutional formats that foster the development of the PSF in Brazil, especially with regard to the issue of the so-called transition of labor relations systems and employment at the national level. The data collected indicate that, in practice, there are different wages from those of the market for the different professional categories, which explicitly favors some people, and at the same time opens space for new institutional forms of labor relations. Thus, the FHS's mission is to restructure the current care paradigm, which prioritizes emergency care, most often in large hospitals. As an alternative, the family becomes a focus of attention in the environment in which it lives which enables a more accurate understanding of health conditions and the disease itself. The program also includes efforts to promote health, prevention, recovery, rehabilitation of diseases and other frequent illnesses. The FHS describes the HUS as a priority strategy for the reorganization of basic care in Brazil, ratifying values such as "universalization, equity, decentralization, integrality and community participation, through the registration and the linking of users" (Reis, Araújo \& Cecílio, 2012).With regard to service delivery, the family health strategy seeks to promote discussions and analyzes regarding the process of changing the health care model that has been in force since the 1970s by all the social actors involved in creating a new paradigm that is capable of enhancing health promotion and protection activities, as well as disease prevention.

These guidelines were been considered as the starting point in producing a positive image for overcoming the old model. By focusing on the family in its physical and social space, this perspective of action in the field of health allows the health team an extended understanding of the health-disease process, which generates new opportunities of an interdisciplinary nature, linking the Social and Applied Sciences to the issues of Health and Demography. This assistance model prioritizes multidisciplinary work, involving physicians, nurses, nursing auxiliaries and community agents, in which everyone must identify with a service proposal that requires creativity and initiative for community work and in groups.

In this case, the work of community agents is extremely important, since they know the characteristics of local reality and are part of the community. It is important to emphasize that their performance represents a unique possibility of bringing into the health teams the way of life of the population, through a look that shows the needs from a point of view from the inside out, allowing a way of approach that broadens the horizons to a new context in terms of intervention. These peculiarities may arouse in the agents the interest of social movements in the search for better living conditions, such as: education, basic sanitation, leisure, work, income and others (Sousa, 2001).

The Ministry of Health supports and encourages this idea by giving some specific attributions to the Community Health Agent (CHA). This job include the translation the social dynamics of the community, their needs, their potentialities and limits into the health team to identify existing partners and resources in the community that can be optimize by teams in addition to promoting education and community mobilization, aiming to develop collective actions for sanitation and environmental improvement(Tavares, 2002). All of these assignments require that theCHA to be a natural leader in the community, based on the ability to communicate with people, to foster co-responsibility in improving the quality of life and health of the population. However, this natural leadership, present in official documents as an attribute, is not real; it is an assumption that is unfounded. Consequently, turning health workers into pro-active subjects should be the central objective of training programs. Community health workers should been trained on the different aspects of the health-disease process. In addition to biomedical knowledge, other knowledge that favors the process of interaction between these agents and families, as well as the identification of their needs, has to be incorporate into their training. For this reason, the understanding of the health-disease process in all its dimensions (biological, social, political, economic and cultural) is important for the adequate planning of health actions based on the reality in which families are been found (Oliveira, Bonfim, Araújo\& Ramos, 2002). 
However, the training of health professionals in many schools is been based on the traditional education model of medical courses, which emphasize biological aspects, fragmenting knowledge and reproducing a compartmentalized, technical and restorative practice.

This type of training does not envisage the importance of the participation of users, families and the community in its own recovery process, and does not encourage community participation to reformulate the determinants that cause health problems. It is worth remembering that most of the professionals who are part of the FHT are been formed based on values that are being passed on to the community agents, inspired by the biomedical health model. The collective discourses show the need for training the community health agents as well asjoint construction of the education program. This effort should have as its main objective to enable them to face the difficulties perceived in community work in order to they recognize and exercise their leadership role in trying to change the determinants of health such as work, salary, living conditions and hygiene.

Based only on the biological medical referral, health professionals feel powerless in the face of human ills and their consequences for communities, resulting in unemployment, lack of hygiene and hunger. For this reason, listening to what the community has or needs to say means welcoming it as a way of taking care of the well-being of this specific locus, and is probably the initial step towards promoting a dialogue capable of generating new ideas and possibilities to be effectively implement.

Popular education does not aim to create educated subaltern subjects: clean, polite, literate subjects, drinking boiled water, eating soy flour, shitting in septic tanks [...] It aims to participate in the effort to organize political work that, step by step, make way for the conquest of his freedom and his rights [...] (Vasconcelos, 1998, p.43).

It is worth remembering that the unpreparedness to work with the community emerges as the result of an educational practice that teaches people to talk rather than talk to them. For this reason, during the implementation process of the training program the participation of community agents is encouraged to develop the autonomy and understanding of individual and collective responsibility in the learning process. Particularly related attributions relate to - the freedom of expression of leaders in the community, as well as the recognition of partners and resources within it for the inclusion of an educational action with the purpose of detecting and solving the problems that arise with the process of economic and social development of each locality.

In this sense, at the same time as a general parameter of the population situation is been drawn in terms of solving the cases served, the agents contribute with the recognition that the success of their work depends on the characteristics of each case. This includes charging for eight daily home visits, respecting the manner of each resident / patient. The so-called home visits at the gate act as a strategy that these professionals employ until they gain the confidence of the families. These daily experiences configure the variables of each case, aiming at the appointment schedule, the medication, as well as the information necessary for good care. In the course of this action, the agents must observe the surroundings of the houses, besides guiding and delimiting the proximity that makes possible the action strategies of the basic procedures to been take to guarantee the health of each community.

Therefore, it is necessary to emphasize that this approach to assisted persons produces a series of effects related to the construction of affective bonds with residents. They often can go beyond the limits of the performance as professionals, giving place to the construction of a friendship in situations that also concern the staff personally, since they face similar situations with friends or family and for putting themselves in the place of those who are suffering or involved in situations suffered. Another aspect related to this proximity is the reversal of roles that leads the population itself to seek the agents of health in their private space to share transformative knowledge and ideas.

Because they are been sought out of working hours due to requests for medication, information or scheduling of appointments at the health center, these agents become a point of reference for residents of a specific locality who end up inviting them for special occasions as well to help solve problems of all kinds. These professionals due to pressure they undergo at work and report the most varied problems, including the lack of structural support, the insufficiency of the technique and of its own effort. Besides, there is the lack of recognition of the actions carried out which ends up generating a sense of frustration in the face of the limits of its function and of the health network itself. Even though they understand that their work cannot be responsible for the transformation of reality, they must be fully aware that their activity functions as a palliative solution, but indispensable in view of the socioeconomic situation of the less favored populations. 


\section{Conclusion}

Due to the territorial dimension and the population diversification of Brazil in terms of basic health needs, a differentiated strategy of action is required for communities at risk, and should been see as an emergency procedure in an attempt to solve the problem of social exclusion that have always plagued the country. Those weakened by misery have a very great difficulty with regard to proper implementation in relation to health care. Therefore, promoting meetings so that these people can reflect and debate about their possibilities of life, leads to the discovery of the best way to act in the collective sense in the search for solutions. This has become the biggest challenge for community agents and health care teams in the country.

It is also worth mentioning that being a community health agent consists mainly of joining efforts in a community, with a view to defending public health and education services and encouraging the participation of all potential beneficiaries of scientific knowledge. Therefore, there must be a continuous movement to ensure that community agents have a permanent form of education and participation, preparing them for the development of their capacities always focused on stimulating and on transformation of their environment. So the reflexive and interventionist community work in practice can provide in terms of solidarity and engagement in the fight against inequalities. To assist these professionals in this difficult but rewarding mission, the Family Health Strategy Program was been designed and put into action at the national level, whose support provides for care in the Basic Health Unit or in the home, according to the needs of each family.

In order to carry out this work in support of community health agents, the Family Health Team, doctors, nurses and nursing assistants have been incorporated into the project, with a view to creating links of shared responsibility and partnerships with the selected locus, so that it is always the most appropriate service for each specific diagnosis. This chain of actions aimed to improve the delivery of services in the health area deserves to be highlight by promoting debate and discussion on the subject and by putting into practice the theoretical assumptions that have helped in the effective transition to the practice of ideas and suggestions. Together with the participation of communities, it can generate new attitudes and decision-making necessary for the well-being of the whole community.

As a conclusion, it is worth mentioning that initiatives of this kind seek to complement traditional knowledge without neglecting the everyday knowledge, "looking to listen" to all those who have some kind of knowledge capable of contributing to the success of these projects. To conclude, this spontaneous interaction between applied knowledge and the understanding of diverse realities found due to Brazilian territorial immensity and its social and economic inequalities can effectively collaborate so that current and future technological advances can reach and benefit the entire population in a fair and equitable way to promote quality of life and human development in the country.

\section{Disclosure}

The authors declare no conflict of interest.

\section{References}

Cardoso de Melo, J. A. (2007). Educação e as Práticas de Saúde. Trabalho, Educação e Saúde: reflexões críticas de Joaquim Alberto Cardoso de Melo. Rio de Janeiro: EPSJV.

Freire, P. (2014). Pedagogia da esperança: um reencontro com a pedagogia do oprimido. Editora Paz e Terra.

Lopes, R. E.,\&Malfitano, A. P. S. (2006). Acción social e intersectorialidad: historia de una experiencia en la interfaz entre salud, educación y cultura. Interface (Botucatu) [online]. vol.10, n.20, pp.505-515. Interface-Comunicação, Saúde, Educação, 10(20).

Machado, M. H. Os médicos e sua prática profissional: as metamorfoses de uma profissão. 1996, 245f (Doctoraldissertation, Tese [Doutorado em Sociologia] - Instituto Universitário de Pesquisas do Rio de Janeiro, Rio de Janeiro).

Oliveira, N. M. de, Bonfim, T. L., de Araújo, A. B., \& Ramos, H. C. (2002). O agente comunitário de saúde: construção da identidade desse personagem híbrido e polifônico. Cadernos de Saúde Pública, 18(6), 1639-1646.

Reis, D. O., Araújo, E. C. D.,\& Cecílio, L. C. D. O. (2012). Políticas públicas de saúde: Sistema Único de Saúde. São Paulo: Unifesp.

Sousa, M. F. D. (2001). Agentes comunitários de saúde: choque de povo (vol. 143). Hucitec.

Tavares, G. A comunicação entre os agentes comunitários de saúde e usuários do Programa de Saúde da Família. 2002 (Doctoraldissertation, Dissertação [Mestrado] - Universidade Federal do Paraná, Curitiba).

Vasconcelos, E. M. (1998). Popular education as a tool for redirecting strategies to deal with infectious and parasitic diseases. Cadernos de saude publica, 14, S39-S57.

Weber, M. (1999). Economia e sociedade: fundamentos da sociologia compreensiva. v. 1. Brasília: UnB, 209-227.

Zappe, J. G., \& Dias, A. C. G. (2010). Delinquência juvenil na produção científica nacional: Distâncias entre achados científicos e intervenções concretas. Barbarói, (33), 82-103. 